\title{
Apprehension Overruled on Data Classification Based on Mental Stress Vectoring
}

\author{
P. Indhumathi, K. Rajeswari
}

\begin{abstract}
Data classification towards mining implies to find many factors to endure and sustain the real factors on the research problem. Many dangerous problematic issues are studied over them which are rolled out on the human life in their day-to-day activities especially for working employers in various sectors, for old people hearing suddenly unexpected news and which cause mental stress to them. The deep study of knowledge is involved to stabilize the importance to protect, prevent and predict the stress issues in detailed design manner. The main focusable approach to analysis the concern regarding manifold factors like age, type of diseases factorized highly with the cause and consequences to cure them by applying new research methods.
\end{abstract}

Keywords: Data Classification, Data Cataloging, Mental stress, Research methods

\section{INTRODUCTION}

The word stress vectors too many factors of ideology to state and define them in technical aspects. The main ideological factor of stress means to define based on burden or rigidity faced by the human which depends on their own surroundings. Some terms about stress state that as "impact" or "pinpointing the force of action" or emphasis on hard emotional feelings. Stresses mainly depend on the time factor and the situation faced on them personally. The definition of stress belongs to "a way of continuous different exploit from the individual from their coping capacity". While speaking biologically, the word stress deals with some emotional action of course that is correlated to mental tension as the prediction. Before starting the survival analysis, some clear terms and its ability has to be drafted or to be studied to prolong the analysis in many classified manners. Some of the terms predicted to survey on mental features are illness, stress, health, disorder and retardation.

Mental illnesses are nothing but their capabilities of the work done on their routine lives with cope or not. Generally, it results in many disorders like eating, anxiety, bipolar, personality and so on. The first cause of illness starts with fear and always having a disturbed mindset of thinking. The main signal of mental illness based on psychology is always feeling the impossibility of thinking.

Revised Manuscript Received on August 25, 2019.

* Correspondence Author

P.Indhumathi*, Research Scholar, PG and Research Department of Computer Science, Tirppur Kumaran College for Women, Tirppur, Tamil Nadu, India

K.Rajeswari, Associate Professor, PG and Research Department of Computer Science, Tirppur Kumaran College for Women, Tirppur, Tamil Nadu, India

(C) The Authors. Published by Blue Eyes Intelligence Engineering and Sciences Publication (BEIESP). This is an open access article under the CC BY-NC-ND license (http://creativecommons.org/licenses/by-nc-nd/4.0/)
Mental stress is related and also related to networking service between a client and server as like request and response.

Mental stresses which can be defined and stated as something abnormal or not able to expose them either mentally or in their physical activities. It imposes with some real mind of events with less dramatic features on our day to day life as our responsibilities. Causes of mental stress deserve to a problem in the digestive system, risk of heart attack, and highly increase your aging process.

Mental health involves based on the mindset of every human, as of how they react for action as applied and feel on it with their original thought process. At some situation, it affects like emotional, psychological and social environments. Mental health mainly depends on age factors from childhood to adulthood. The main causes of the mental health is affected to any type of diseases which relates and depends on their family background and issues, their own life experience and mainly expand from their biological factors based on their genes as a microarray. Mental disorder is related or depends on the mental illness which widely ranges from their health conditions. Disorder reveals to their own mind thoughts, behavior and their own mindset. Causes of disorder expand in many ways as apprehension, downheartedness, not eating well and have some addictive behaviors. Mental Retardation (MR) is called as a general learning disability, and affects based on the nerve system with its crashed development with disorder categories with some signaling features with unpaired intellectual and adaptive functioning. This can be affected with many stages from mild to serve based on Intellectual disability and possibilities are there to turn around them into as an normal human being with proper follow-ups and intervention cared over them to stabilizes their life.

\section{PROBLEM STATEMENT}

The main objectives are to focus on the research work relates to mental stress. The deep study is required and some background analyses towards the medical factors based on the cause over to them to reveal it as a positive vector analysis. Multiple factors and parameters are analyzed to apply in the research work to stabilize the cause in a positive solution to release the mental stress in an easy way.

The research reveals based on the purpose of the problem statements are:

Engineering

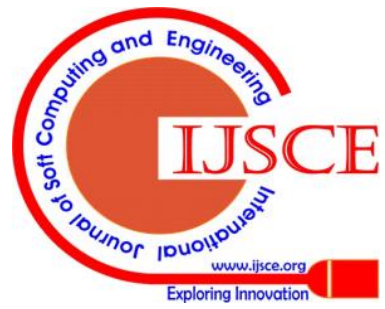


$\checkmark \quad$ What age factor people are highly affected with mental stress?

$\checkmark \quad$ What cause of syndrome highly recommends?

$\checkmark$ How the classification depends and belongs are correlated to mining features?

$\checkmark$ How analyzation over them is applied as such while detecting is easy unless to cure?

$\checkmark$ Determinations over the statistical value are factorized to provide visualization dependences over the attributes like age, gender, diseases and so on.

\section{IMPLEMENTATION ANALYSES}

The vectoring analysis focused on the research work as a starting stage from the various attributes as applied towards the value and the level of the stress as predicted to classify. The prolong study in the deepest manner will definitely substitute some solution to resolve from the stress from the different environment. The pre-planned execution flow of the research methods depends the vector sets are age, gender, syndrome test, mental ability test, mind thinking test, disease analysis and etc.

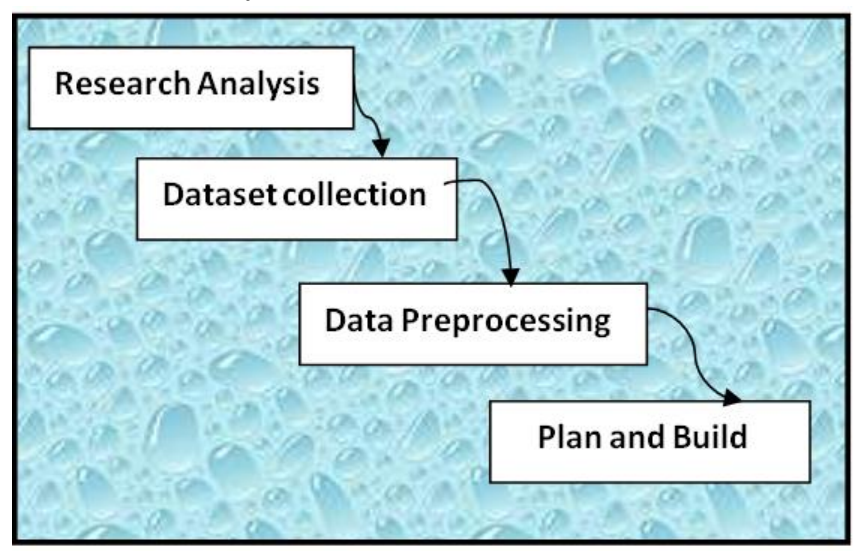

Figure 1: Execution flow of the research process

The research analysis starts with the knowledge gathering towards the dataset collection with its attributes as a deep study, in which any correlated features are appeared to paths into any formulation process to proceed further. Gathered data are then planned for preprocessing to make unknown data into meaningful data. Data classification is planned to apply as a new insight towards to classify the model with the attributes defined to build and configure the features literally into quantifiable value. To forecast the data based on the cataloging as occurred towards mental stress can be factorized either based on binary classification, multiclass classification or predicted class classification which mainly depends upon the facts and figures which turns around some statistical values which will be useful to evaluate from the supervised learning features as an origin. Some of the technical aspects proved the intervention on visualization based on stress and non-stress in a statistical manner. Another way of mental stress is studied over based on their factors are happiest life living, worthwhile, joyfulness, and anxiety. From the study cross, stress is not affected in most of the cases of cataloging with non-stress whereas stress belongs to be at a moderate level i.e., below the average stage.

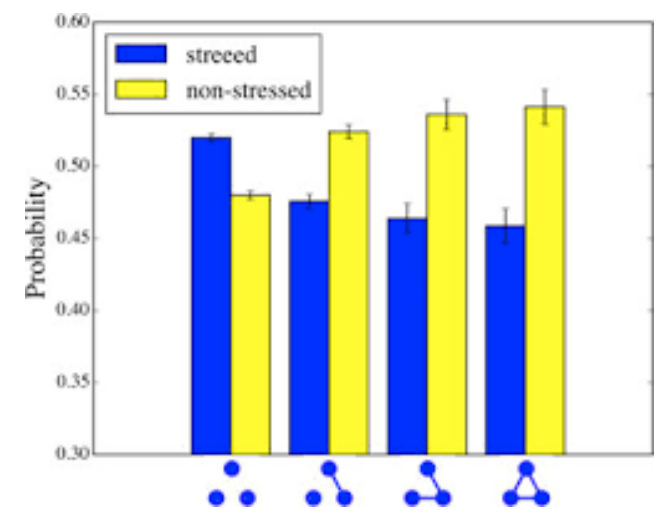

Figure 2: Probability analysis

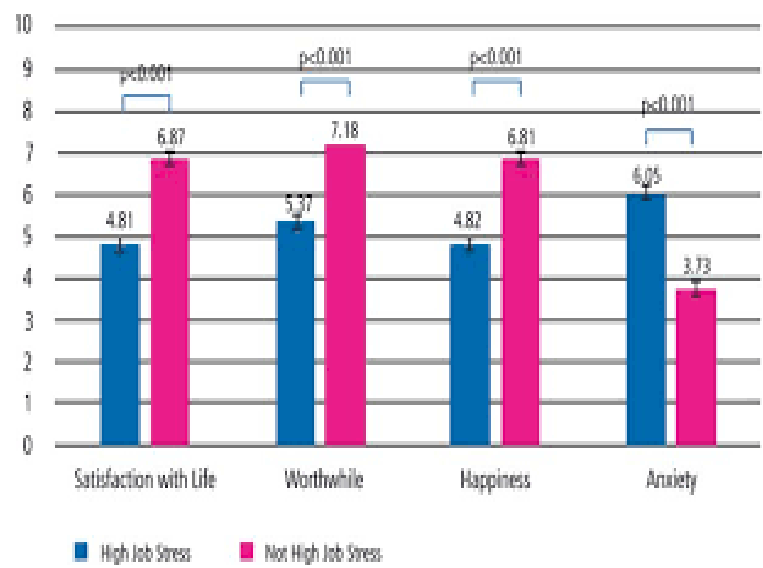

Figure 3: cataloging stress categories

\section{DEPENDENCY OVER DATA CLASSIFICATION}

A short revise followed through the dependency features to highlight supervised learning a label with the attributes to implement. As such data classification plays a vital role to evaluate the data science in a new form to apply the new model to classify the data. Data Classification can be applied by comparing the training set with the test set, exactly to predict the model for the solution. First of all, dependency over the classification can be analogized based on the research methods, data classification in data mining and mainly depends upon the subject matter in mental stress. The classifications over the research methods are of many types, among the features the highlighted features are descriptive, analytical and statistical.

Descriptive - relates to the purpose of the surveys, which imposed the facts as results.

Analytical - relates to establishing the fact-finding as why and how it can be

Statistical - relates to cataloging the features to group the data according to the similarities to output a useful data

Published By:

Blue Eyes Intelligence Engineering

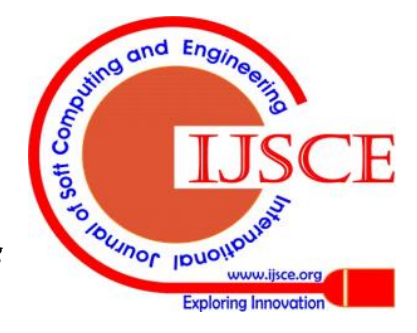


Data Classification is required as much as to prove or cross-check the hypothesis as estimated towards the research plan at any stage of processing. The focal point of data classification in data mining is to collect the data or information as per the required criteria, then move the data towards data into classes. The data classes will supports to predict the result as much as accurate. The various ways of data classification methods used in data mining are decision trees, Boosted trees, Random forest, and Support vector machines. Linear classifiers, neural networks and soon.

The process of evaluation planned to implement towards the decision trees to prior the study of attributes well and in the detail , which supports to sustain the facts of result with estimated working hypothesis. The next level of application on data classification is planned towards depends on the Bayesian classification, which exactly pinpoints the dependency relevance and non-relevance of the attributes towards the class value in the way of statistical classifiers methods. The final factors of evaluation can be applied survived towards the rough set approach like either lower or upper approximation of the data classes.

Basic terms of factors privileged about mental stress are studied in terms of its causes, syndrome, the disease affected and treatment. The main cause of mental stress exactly depends upon the situation faced in their human life. The following table will highlight some details about the metal stress features as below:

Table 1: Catalog of mental stress Identification

\begin{tabular}{|c|c|}
\hline Mental Stress & Features Related To Mental Stress \\
\hline Causes & $\begin{array}{l}\text { Change of the environment in life, Any } \\
\text { hypothetical situation, Loss of money or job or } \\
\text { any prized one, Feeling alone in life, Workload } \\
\text { in the job and so on. }\end{array}$ \\
\hline syndrome & $\begin{array}{l}\text { mood upset, misbehaving, tension irritability, } \\
\text { anxiety, memory loss, not able to concentrate } \\
\text { properly }\end{array}$ \\
\hline $\begin{array}{l}\text { Disease } \\
\text { affected }\end{array}$ & $\begin{array}{l}\text { Acne, Headache, Often get sickness Digestive } \\
\text { problem ,Appetite (weight increase) } \\
\text { Fast heartbeat. Depression, Sweating, Changes } \\
\text { in hormonal features, Chronic pain }\end{array}$ \\
\hline $\begin{array}{l}\text { ways to avoid } \\
\text { mental stress } \\
\text { (treatment) }\end{array}$ & $\begin{array}{l}\text { Doing exercise, change the surroundings, spoke } \\
\text { with anybody open-heartedly, have a bar of } \\
\text { chocolate or coffee, taking supplements with } \\
\text { doctors supports, avoid the hypothetical } \\
\text { situation }\end{array}$ \\
\hline
\end{tabular}

The crossways based on mental stress are applied in a generalized manner of approach. The proposed view stepped towards a specialized view by catalog the mental stress situation in various factors like age, gender and exactly based on the workload to the human with their potential fulfillment with their cause with the survival vectors.

\section{CONCLUSION}

The probability analyses manner of mental stress varies from one catalog to another catalog, which extremely depends upon the feature which we evolved in the data classification. Even then stress is a very important factor to sustain life in an easy way of leading with Positive aspects. Many conjectural situations make as stressed in our human environments. In the future evaluation of the research process is planned to expose and expand the supervised learning of the data well-classified approach to reduce from the moderate to very mild stage

\section{REFERENCES}

Amir Mohammad Shahsavarani, Esfandiar Azad Marz Abadi, Maryam Hakimi Kalkhoran, "Stress: Facts and Theories through Literature Review", International Journal of Medical Reviews, Volume 2, Issue 2, Spring 2015; 230-241

2. Hem Jyotsana Parashar, Singh Vijendra, and Nisha Vasudeva, "An Efficient Classification Approach for Data Mining", International Journal of Machine Learning and Computing, Vol. 2, No. 4, August 2012

3. Ritika ,'Research on Data Mining Classification" International Journal Of Advanced Research in Computer Science and Software Engineering". Vol 4,issue 4,Apr 2014

http://www.microsoft.com/sqlserver/en/us/solutionstechnologies/SQL-Server-2012-business-intelligence.aspx

5. World health organization,2014 WHO-Mental health : a state of wellbeing

6. Ahmed Husseini Orabi,'Deep Learning for Depession Detection of twitter users"

7. https://towardsdatascience.com/data-visualization/home

8. https://en.wikipedia.org/wiki/Mental_disorder

9. https://towardsdatascience.com/data-science/home 